\title{
LA AMISTAD COMERCIAL COMO EXPERIENCIA SOCIETARIA: EVIDENCIAS DESDE CHILE ${ }^{1}$
}

\author{
Nicolás Gómez ${ }^{2}$ \\ Tania Encina ${ }^{3}$ \\ Rocío Mieres ${ }^{4}$ \\ Camilo Lazo $^{5}$
}

\section{Resumen/Abstract}

El artículo describe la amistad comercial que se desarrolla en los procesos productivos de la editorial independiente. Esta dimensión es revisada con respecto a sus pares y a las motivaciones individuales. La metodología usada fue cualitativa, los datos provienen de nueve entrevistas realizadas a integrantes de la organización Cooperativa de trabajo Agrupación de editores de la Furia. Los resultados se presentan a través de siete arquetipos que son resultados del análisis estructural de contenido, cada arquetipo corresponde a una dimensión de la amistad comercial en tanto estructura de orientación objetiva en el mundo de la vida económica. Las conclusiones se refieren a las representaciones de la amistad comercial en la producción de bienes simbólicos y como criterios de la participación democrática.

Palabras claves: editorial, bien común, amistad comercial, libro, bibliodiversidad.

\section{COMMERCIAL FRIENDSHIP AS A CORPORATE EXPERIENCE: EVIDENCE FROM}

CHILE

The article describes the commercial friendship that develops in the production processes of the independent publishing house. This dimension is reviewed with respect to their peers and individual motivations. The methodology used was qualitative, the data comes from nine interviews with members of work organization the Cooperativa de Trabajo Agrupación de Editores de la Furia. The results are presented through seven archetypes that are results of the structural content analysis, each archetype corresponds to a dimension of commercial friendship as an objective orientation structure in the world of economic life. The conclusions refer to the representations of commercial friendship in the production of symbolic goods and as criteria for democratic participation.

\footnotetext{
${ }^{1}$ Este artículo es un resultado de la investigación financiada por el Concurso Internos de Proyectos I+D, año 2017, (CIP2017003), de la Universidad Central de Chile, y del patrocinio de la carrera de Sociología de la Faculta de Educación y Ciencias Sociales de la misma universidad.

${ }^{2}$ Universidad Central de Chile, chileno, nicolas.gomez@ucentral.cl

${ }^{3}$ Editora Das Kapital,chilena, tania.encina@gmail.com

${ }^{4}$ Universidad SEK, chilena, rocio.mieres.v@gmail.com

${ }^{5}$ Universidad de Chile, chileno, camilolazog@gmail.com
} 
Keyword: editorial, common good, commercial friendship, book, bibliodiversity

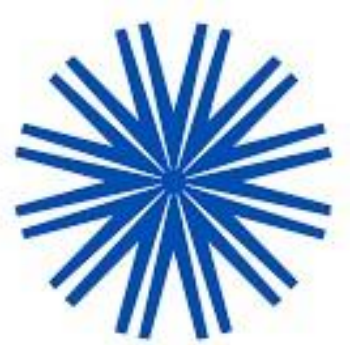

Introducción

En los estudios de las economías la revisión de la amistad comercial puede seguir la hipótesis plateada por Tönnies, según la cual cada organización donde sus propietarios son también sus trabajadores recurre a las "exigencias del sentimiento de deber" del compañerismo, la fraternidad y la cooperación que se expresan en una ética que limita, pero no elimina, la racionalidad instrumental o la orientación utilitaria. Gracias a lo cual, se construyen las asociaciones (Tönnies, 1942:67,89).

En este artículo presentamos una descripción del repertorio de categorías que articulan el sentido atribuido a la amistad, las cuales expresan el simbolismo colectivo que está en el campo de experiencias sociohistóricas. Para observar ese ámbito de la amistad comercial, trabajamos sobre los códigos sociolingüísticos que son usados por las personas que participan en una organización editorial, para interpretar las relaciones de producción que están en una zona difusa entre su intimidad y las esferas de la vida comercial; y que también asisten a la construcción de la Cooperativa de editores de la Furia en Chile. Debido a este enfoque, en este artículo no aportamos datos sobre las relaciones de competencia de las editoriales o sobre la incidencia del poder en las trayectorias de esas organizaciones.

En 2009 se realiza la primera versión de la Furia del Libro, una feria conceptualizada como un espacio de comercialización para pequeñas editoriales que no podían asumir costos de participación en ferias como la FILSA (Feria Internacional del Libro de Santiago). En esa instancia es que un grupo de editores se conoce y decide aunar fuerzas para hacer frente a las difíciles características del mercado del libro en Chile. Así, finalmente, en 2013 -oficialmente 2014-, aparece la Cooperativa de trabajo Agrupación de Editores de la Furia, tomando el nombre de la feria como símbolo de identificación ${ }^{6}$.

La Cooperativa de editores de la Furia (CEF), reúne a las mujeres y los hombres que ya se desempeñaban como editores de libros y dueños de una de las 41 organizaciones que la constituyen. El boom de las

\footnotetext{
6 En la actualidad existen cuatro organizaciones representantes de la industria del libro en Chile: Editores de Chile (reúne cerca de 60 socios entre pequeñas y medianas editoriales independientes y universitarias); la Cámara chilena del Libro (conformada por editores, libreros y distribuidores); la Corporación del libro (construida por editoriales como Planeta, Random House y otros editores); y la Cooperativa de Editores de la Furia (conformada por cerca de 40 editores independientes).
} 
editoriales culturales (también llamadas microeditoriales o editoriales independientes), es un proceso que está creciendo desde hace más de diez años en Chile y otros países del cono Sur y Europa, conformado principalmente por propuestas que vienen a complementar y desarrollar un nuevo trabajo en el campo de la edición, apoyándose muchas veces en sistemas de producción artesanal, grados variables de autogestión y la apuesta por catálogos capaces de introducir dinamismo a escenas literarias que aparecían de capa caída, corriendo los riesgos inherentes a la publicación de autores y apuestas de rescate patrimonial, así, el panorama y la relación en el mundo del libro ha cambiado significativamente. Cabe preguntarse si discursiva y prácticamente estos proyectos editoriales constituyen en efecto un fenómeno contracultural o de cierta proyección política. Entendiendo las grandes limitaciones que enfrentan los editores culturales, sus ejes de trabajo han girado históricamente en el planteamiento de discursos críticos, fundamentalmente mediante la publicación de autores inéditos o que trabajan temáticas instaladas fuera de los marcos de referencia e interés de las gerencias comerciales de las trasnacionales. En este sentido, uno de los logros más relevantes de las editoriales culturales ha sido, aunque mediante una práctica muchas veces errática, romper efectivamente el cerco en torno, en primer lugar, a los espacios de la crítica, y en una segunda instancia, aunque aún no del todo desarrollada, a los propios lectores, generando nuevos espacios para la circulación continental del texto, principalmente en géneros abandonados por el circuito comercial, como la poesía y, algo más atrás, el ensayo. Esto ha representado una real dinamización de las estéticas literarias de cada país, las que hasta hace no demasiado tiempo, han ido encontrando maneras de agrupación y formas de cooperativismo -incluso levantado desde las políticas públicas gubernamentales bajo el modelo de "autogestión y emprendimiento" en varios países.

Según Symmes (2015), estas organizaciones no entregan los recursos monetarios para el sustento de los editores, por lo cual, ellos realizan otros desempeños laborales asalariados para satisfacer las necesidades de su hogar y familia. Además, sus publicaciones son esporádicas, con baja cantidad de ejemplares y su modo de producción es semi-artesanal.

Symmes subraya que este tipo de desempeños y las organizaciones que se articulan a su alrededor, surgen sistemáticamente y han usado el nombre de "edición independiente" para ubicarse en los mercados internacionales. Esa posición sería un resultado del capital simbólico transaccional cuya fuente son las experiencias de trabajo asociado; y, por otro lado, develan las condiciones del mercado neoliberal chileno, porque muestra la iniquidad de acceso a los bienes simbólicos, exhibe los monopolios que controlan la 
impresión, los lugares de venta de los libros y los contratos con el sector público (Symmes, 2015; 2013). También la descripción hecha por Symmes nos indica una posición en el mercado de libros, la cual es habitada por las editoriales asociadas en la CEF, esa posición se caracteriza porque ahí están los editores que consideran que el libro es más que una mercancía y que su elaboración es un proceso creativo que es diferente, incluso opuesto, a la reproducción de un tipo ideal de libro que sí, y siempre sí, pretende asegurar el éxito de venta y las ganancias monetarias para los dueños de las empresas editoriales transnacionales. Como ha demostrado Callon (2007), cuando el mercado realiza recortes en la realidad productiva o comercial, está alentando las trayectorias de algunos de sus participantes y, al mismo tiempo, está creando las condiciones para que se organicen grupo de interés. En el mercado de las editoriales, el contenido de interés y en disputa es la bibliodiversidad, y por supuesto, las interacciones donde se agencia sociotécnicamente la politización de la esfera pública dentro del mundo del arte y en los diferentes espacio societarios donde el consumo de bienes simbólicos es una regularidad, tanto porque satisface los gustos personales, o el placer de leer y escribir; o porque entrega información útil y pertinente el reconocimiento colectivo que favorece acumular prestigio.

En consecuencia, al estudiar la amistad comercial también estamos indagando sobre las tensiones que experimenta el sentimiento de deber cuando es desempeñado en mercados articulados por una tecnología social de "oferta-demanda-precio" (Polanyi, 2009, p. 216), donde el dinero (metálico, papel o plástico) es fundamental y sus interacciones apuntalan el compromiso breve entre las personas, la despolitización de los contenidos de las interacciones y el cálculo utilitario del agente egoísta (Gibson y Graham, 2011). Y desde luego, estamos invitando a reflexionar sobre cómo los códigos sociolingüísticos que expresan la amistad comercial dan sentido a los editores para ingresar en las disputas por el espesor del campo de sentido al cual recurren las personas para indicar los componentes de su mundo, incluyendo esos mundos posibles que inspiran la conducta altruista y utópica.

\section{La amistad comercial como relación societaria}

La amistad comercial de los editores es una condición que participa en la gestión de sus editoriales, su presencia es notable porque se diferencia de otras actividades como la realización y supervisión de los contratos con las imprentas, cuando se pagan los gastos fijos que aseguran un espacio físico para las reuniones del gobierno corporativo donde ellos reflexionan y deciden sobre el catálogo, también se 
distingue de la distribución de los libros, de los acuerdos con los dueños de las librerías y de la cobranza. En este trajín, la amistad comercial es un recurso que es diferente al mostrado por los otros factores productivos como el capital, la tierra y el trabajo. Al seguir los supuestos de Max-Neef, Elizalde y Hopenhayn (1993) sobre los recursos no convencionales de la economía, asumimos que la amistad aumenta su complejidad y trayectoria al ser usada, y las personas pueden crearla porque aprenden sobre su comportamiento.

En el análisis de Simmel (2002), la amistad comercial es una manera imperfecta de sociabilidad porque si bien logra un valor, un tipo de felicidad que depende de la felicidad de los otros y que adquiere vida propia al independizarse de las expresiones materiales del "estar uno con otros, uno para otro y uno contra otro"; no va más allá de las actividades que realizan los contenidos e intereses individuales, porque mantiene la reproducción de una finalidad. Pero estamos dispuestos a asumir que la amistad comercial está lejos de ser una expresión de la interacción instrumental, o puramente dotada de contenido diría Simmel, que busca un fin para luego desaparecer.

En los encuentros especiales, cuando hombres y mujeres se han conocido gracias al ejercicio de un conocimiento técnico como el ser editores, la amistad comercial favorece la mutua determinación, así la unidad tiende a desdibujar y suprimir las motivaciones de la unión y a consolidar la fuerza y eficacia de la conexión "libremente flotante y de interacción recíproca entre los individuos", la cual disuelve todos los contenidos de la finalidad en la forma (Simmel, 2002, p. 83).

Para Simmel, esta experiencia de sociabilidad lúdica que aplaca las egolatrías de las personalidades que sostiene el valor en sí de la relación de estar juntos, donde el "sentido del tacto" cumple un papel esencial al guiar la autorregulación de los individuos involucrados (Simmel, 2002, p. 84,85), es un mundo artifícial porque no tiene fricciones; y, al rotar en torno a la idea de amistad, esta categoría ahora dominante se vuelve fuerza productiva porque acoge la vida, la cual deberá acomodarse al interior de esa idea de amistad de ahí en adelante (Simmel, 2004, p. 55).

En las indagaciones de Becker (2008) sobre los mundos del arte, la amistad comercial está oculta como un dato dado en la realidad que él estudia. Esta invisibilidad de la amistad se comprende porque su investigación busca reconocer las expresiones materiales que participan en las decisiones durante la 
elaboración de la obra de arte. Desde nuestra perspectiva, la amistad comercial es una experiencia prereflexiva a la luz del estudio de Becker, y contribuye a sostener el conjunto finito de interacciones de las redes donde se realizan los apoyos al artista; y al igual que las demás variables, participa en el resultado final que él logra.

A nuestro entender, este énfasis usado por Becker vuelve sobre la distinción de Simmel, es decir, la amistad comercial es diferente a las prácticas que expresan los consensos y las convenciones de los vínculos cooperativos en el arte, los cuales ayudan a fijar las formas de transmitir las ideas y las experiencias, también a declarar las obligaciones y los derechos de los artistas y del público y, especialmente, a promover los "momentos editoriales" que los involucrados manejan gracias a que comparten un conjunto de "vaguedades confiables" para construir la obra de arte (Becker, 2008). Incluso agregaríamos, parafraseando a Salas (2006, p. 173), como todo mundo de la vida tiene su propio sentido común, es ese mundo el que ofrece las razones para que participen los que ahí viven, de ahí que para los editores ese mundo es vital.

Entonces, la amistad es una relación diferente que prescinde de la obligación y del control social, alejándose del hábito (Dreher, 2012), y puede estar animada por la admiración de las capacidades específicas de otra persona. En nuestro caso, de otro que se desempeñan como editor y dueño de una editorial. Desde aquí es posible advertir que los editores están predispuestos a trascender su organización y los vínculos asociativos entre organizaciones porque sus formas de estar en los mundos del arte y de las economías, cuentan con símbolos de amistad donde coexiste lo representado y la representación (Bialakowky, 2012), y cuya fuerza favorece una cosmovisión orientada a empujar prácticas que benefician a la colectividad. Por ejemplo, para jugar a favor de la bibliodiversidad. Y los alienta a tomar compromisos no comerciales, o sea, se "autoasignan funciones morales, ciudadanas y patrimoniales" (Symmes, 2015, p. 337)

En este nivel del argumento, Dreher nos propone que la simbolización de la relación nosotros en el mundo de la vida, debe ser entendida como el resultado de esos compromisos que develan una sintonía social y espiritual entre personas que se ven reflejadas en las otras personas. Por lo tanto, la amistad comercial asiste al científico social que busca explicar la integración sociotécnica de los que se han especializado en la producción de un bien o servicios, porque dicha actividad crea una simbolización de la relación-nosotros 
que tipifica a todos los que se acompañan en el oficio. En nuestro caso, el oficio de crear un libro introduce a los compañeros en la participación dentro de ese mundo de estructuras de orientación objetiva, de acción intersubjetivas de la amistad y de realidades sociohistóricas inherentes a lo que llamamos: la vida de los editores.

Cuando Dreher sigue a Schütz (2012), asume que la amistad es una noción que trasciende el mundo de la vida cotidiana de los individuos y en tanto forma especial de encuentro produce un lazo específico entre las personas que va más allá del tiempo y el espacio, es por esa cualidad que la amistad puede ser reactivada después de un largo tiempo a partir de una idea de amistad que, al ser nuevamente constituida, forja la cotidianeidad del lazo social. Aún más, también la amistad es un lazo durable porque sus actos articulan varias biografías que construyen una experiencia común gracias a una semántica que hace posible la comunicación sobre esos asuntos de manera retrospectiva, especialmente cuando la persona debe dar una respuesta al ser requerida por una definición de amistad y recurre a la apresentación de ese amigo o amiga que acompañó el desenlace de las experiencias; y para reconstituirla vuelve sobre la idea del compañero o la compañera que es el símbolo de la relación-nosotros.

Habitualmente esos relatos ingresan a un ritual de narraciones que pasan una y otra vez, a modo de reproducción simbólica de la amistad; y así las narraciones participan orientando las acciones cotidianas. De ahí en adelante, agregará Dreher, la idea de amistad excede la situación individual dentro de la esfera cerrada de significados de la realidad eminente, por lo cual, la amistad logra una calidad extracotidiana (Dreher, 2012). Según Torterola, esa es la expresión de una "comunidad evocada" (2012, p. 120-121).

Además, Dreher asume que la amistad puede manifestarse a través de múltiples arreglos empíricos que mantienen elementos comunes. Esto sería factible porque "las propiedades objetivas de las realidades sociohistóricas están basadas en estructuras universales de orientación subjetiva en el mundo". Entonces, el espacio y el tiempo fijan estratos en la conciencia social. Así, en la amistad, la distancia espacial no tiene relevancia porque la amistad confiere intimidad a los involucrados hasta alojarlos en la familiaridad. Esta familiaridad supone que los involucrados comparten una memoria sobre las experiencias vividas o, al menos, pueden identificarla y asignarle una interpretación que la vuelve significativa y así objetivan sus interpretaciones y rasgos emocionales. (Dreher, 2012) 
Las descripciones conceptuales hechas hasta aquí aportan argumentos a la siguiente pregunta: “¿cuál es la fuente de donde deben proceder aquellos valores comunes con los que poner en marcha el intercambio entre vínculo comunitario y participación?” (Honett, 1999, p. 14). Entonces sugerimos lo siguiente, la amistad predispone a la participación democrática para lograr una comunión de propósitos, con prescindencia de la consanguinidad y la vecindad. Este desempeño de la amistad es notorio en sociedades diferenciadas, donde la secularización ha promovido conductas utilitarias y hedonistas, porque la amistad comercial permite cerrar la totalidad de ese mundo significativo, y bajo ese proceso se transforma en acto trascendente.

\section{Diseño metodológico}

Los datos de este artículo provienen de una investigación realizada entre 2017 y 2019, la cual buscó responder la siguiente pregunta, ¿qué dimensiones de la autogestión productiva permiten comprender la trayectoria de una organización económica? El referente empírico fueron las editoriales asociadas a la Cooperativa de editores de la Furia, las que a la fecha de realizar el estudio llagaban a 41. Estas organizaciones tienen en común seis cualidades: 1) las relaciones productivas trascienden el parentesco y la consanguineidad de los integrantes, 2) cada editorial y la cooperativa, toman riesgos comerciales, 3) hacen esfuerzos por mantener la producción continua de libros, 4) buscan promover la economía local, el cuidado medioambiental o el mejoramiento de la calidad de vida de los habitantes, 5) los trabajadores y propietarios de cada editorial deliberan sobre el proyecto económico y 6) las editoriales tienen más de tres años de funcionamiento.

En este artículo usamos los resultados del análisis estructural de contenido aplicado a las entrevistas de nueve editoriales de la Cooperativa de editores de la Furia. Este resultado se logró con el siguiente procedimiento. Primero, el análisis estructural de red mostró que los nodos de estas editoriales favorecían la transmisión de contenidos para la gestión de la cooperativa y en la difusión de los libros y actividades de las editoriales. Aquí las fuentes de información fueron los sitios digitales alojados en la Internet: páginas web de la editorial y espacio de Facebook. En un segundo momento, a través del análisis de entrevista, reconocimos la amistad comercial mediante los códigos sociolingüísticos que manifiestan la existencia de esas experiencias y que se distinguen del capital social, debido a que los entrevistados no las asimilaron a una definición de recurso, así como lo ha estudiado Durston (2000, 2001 y 2005); y en las conversaciones espontáneas esas experiencias de amistad se las excluyó de la interpretación instrumental de las 
interacciones. Incluso, cuando eran narradas se las alejaba de la razón utilitaria. Posteriormente, el nivel semántico de la amistad comercial fue eficiente para comprender las prácticas productivas que no entregan beneficios monetarios a los entrevistados, y cuyo argumento es: "hacer los libros porque sí", por gusto, goce o para aprender.

Es relevante señalar que los pasos seguidos hasta aquí son similares al procedimiento usado por Cederholm y Hultman (2010) cuando emplean el "boundary work as a second analytical focus".

Además, las editoriales seleccionadas comparten las siguientes cualidades: participan en el gobierno de la Cooperativa de editores de la Furia, poseen experiencia en el trabajo asociado con otras editoriales, cada una es reconocida como una organización que tiene el saber hacer y puede enseñar a producir libros, y sus desempeños sostienen la comunidad efectiva hacia dentro de los trabajos asociados en la cooperativa y, al mismo tiempo, promueven comunidad societaria al participar en relaciones intersectoriales que articulan una parte de lo que llamamos como "campo intelectual" (Bourdieu, 2002) o "mundos del arte" (Becker, 2008); y estos desempeños emparentan a las editoriales estudiadas con las organizaciones de la economía popular que dan vida a la autogestión comunitaria (Gómez, Rojas, Benítez y Sánchez, 2019).

En un tercer momento identificamos las categorías sociolingüísticas que ayudaron a construir siete arquetipos, cada arquetipo es una estructura de representación que usan los editores al revisar sus experiencias con los escritores, los textos y otros editores, y se ubican en un espacio simbólico articulado por las relaciones de complementariedad y oposición de códigos que ordenamos en un cruce axial titulado: "Hacer libros porque sí".

Este cruce axial está conformado por los siguientes códigos: "hacer libros", catálogos de nuevas lecturas y editorial independiente. Estos códigos son cualificados por los siguientes criterios: "ganas", "inquietud", “querer", "preocupación”, "necesidad" e "interés”. En oposición a estos códigos y constituyendo otro espacio simbólico en el cruce axial "hacer libros porque sí", están los siguientes códigos: "editorial grande", catálogo de "éxito comercial" y reproducir libros. Estos códigos son cualificados por los siguientes criterios: desgano, tranquilidad, despreciar, calma, opulencia y apatía. 
Hipotéticamente, esos elementos construyen representaciones de la realidad gracias a que promueven juicios que clasifican las prácticas productivas durante el trabajo editorial, y así son consideradas como: buenas, necesarias, justas, inútiles, accesorias o injustas. Aún más, podríamos agregar que expresan la visión política de los editores sobre el deber ser y el saber actuar la amistad en los mundos del arte. Y si llevamos esos contenidos de los arquetipos a nivel de las razones prácticas, esos relatos son los soportes sociales donde se construye una parte de la identidad del editor independiente, permiten la formación de normas, modelos ideales de empresas editoriales y participan en la legitimación de los ejercicios de creación de nuevos valores en los mercados del libro.

\section{Resultados}

Los resultados indagan en la relación del editor con su trabajo y la motivación de su quehacer individual, el cual se refleja dentro del abanico de pares con los cuales se relaciona, siguiendo el motivo de la autocorrección y la elaboración de sus intereses que se plasma finalmente en sus catálogos. Esta relación que se crea producto de las experiencias tanto individuales como colectivas representa en el ámbito simbólico el sentido de la bibliodiversidad, entendiéndolo como la disputa por el campo semántico y estético, y como la transgresión al sistema de producción de libros, internalizándolo como una producción alternativa y personal. En el oficio editorial, cada catálogo va construyendo una manera de interpretación del mundo, un levantamiento de información que es transmitido por el lenguaje, generando una estampa de la realidad contemporánea y en ese espacio el libro es una huella latente de esa transferencia. Los beneficios simbólicos de un capital intelectual construyen así el reconocimiento identitario entre las personas generando comunidades.

En el caso de los editores que estudiamos, la respuesta práctica se inicia con el valor que cada uno le asigna a las consecuencias de la lectura, especialmente a la posibilidad de difundir los contenidos que provienen de la experiencia de los escritores o de la ficción de su trabajo creativo. Los editores también suponen que hay cambios en la reflexión o en la emoción del lector, así como les ha sucedido a ellos. Estas cualidades nos permiten ingresar a un entramado de interacciones entre editores y describir el origen del sentido que justifica que esas personas destinen parte de los recursos monetarios que obtienen en otros empleos para continuar con el proyecto editorial. 
Los editores explican su desempeño a partir de una cantidad creciente de personas que están escribiendo "nuevas lecturas". Esas creaciones literarias están en los asuntos tratados en sus encuentros en un tiempo que ellos reconocen como la "moda" de hacer una "editorial". Es indudable que cada editor, a su manera, busca subrayar ese tiempo pasado, donde fue novedad encontrarse en una ruta de prácticas para el tratamiento del contenido y la materialidad del libro. A partir de estas experiencias, el tópico de la amistad adquiere relevancia porque organiza un continuo semántico que en un extremo tiene las reflexiones sobre las relaciones entre: escritor, texto y editor, sin considerar el papel que cumple la cadena de distribución del libro y el lector, y donde es posible que la siguiente frase sea su resumen: "hacer libros porque sí". Mientras que en el otro extremo semántico se ubican las relaciones de la distribución de los libros y con los vendedores de libros. Aquí, la expresión que resume la situación es la siguiente:

No olvidar que el libro es también un producto, que los libros que no se leen al fin no existen, que el librero es tu mejor lector y amigo, y que el trabajo de editar un libro no termina cuando este sale de imprenta, ni el día de su lanzamiento. (E)

La descripción de la amistad comercial se despliega mediante siete arquetipos. Cuatro arquetipos articulan "hacer libros porque sí", estos son: la construcción de lo diferente desde lo que yo quiero publicar, la construcción de lo diferente siguiendo el proceso de otras editoriales, la construcción de lo diferente gestionado por las mujeres y hacer libros como un medio de autoformación. Y tres arquetipos corresponden a la amistad en las prácticas de trabajo, estos arquetipos son: la amistad como sustento del trabajo editorial, la amistad como situación donde se plantean soluciones a los problemas del proceso productivo y la amistad como resistencia.

A continuación, vamos a describir las interpretaciones que los editores tienen sobre "hacer libros porque sí", debido a que en ese ámbito la amistad comercial es representada como una experiencia societaria. En esta descripción usamos tres pasos. Primero, exponemos un arquetipo que es el resultado de la clasificación de los contenidos de las entrevistas y que se refiere a un mismo conjunto de hechos o ideas. En el segundo paso presentamos la reconstrucción del discurso que se liga con la definición del arquetipo y en el tercer paso exponemos los extractos de las entrevistas que son los referentes empíricos de los arquetipos. 


\section{"Hacer libros porque si"}

La aproximación entre las personas que se van trasformando en editores ocurre gracias a los resultados de un diagnóstico que se hace en las reuniones dedicadas a tratar los mundos del arte, esos encuentros funcionan como dispositivos de co-construcción de conocimientos sobre las oportunidades y deficiencias. En nuestro análisis, el ejercicio de reconocimientos de las deficiencias es el que lleva a los editores a diseñar horizontes de sentidos donde imaginan las prácticas que resuelven esas deficiencias. Entonces, es factible construir cuatro arquetipos que expresan diferentes matices del eje semántico: "Hacer libros porque sí".

\section{Arquetipo A: La construcción de lo diferente desde lo que yo quiero publicar.}

Hay dos ideas que sostienen el sentido, una de ellas es similar a construir o elaborar y la otra es sinónimo de ganas o querer; su combinación mezcla el nivel cognitivo con el nivel emocional, y hay una frontera que indica la necesidad individual o colectiva de distanciarse de otros que también construyen bienes simbólicos. En cuanto a la reconstrucción del discurso, la expresión de este arquetipo sería la siguiente: tenemos ganas de construir cosas distintas y que sean las que yo quiero publicar. $Y$ ese contenido se puede encontrar en opiniones como la próxima:

Editoriales chiquititas que no tenían personería jurídica. Solamente hacían libros porque sí, pero nunca como que se habían planteado el tema de entrar a una cadena de comercialización finalmente. Entonces, pero también como que en un momento como que hubo un boom de editoriales, como que la cosa se puso de moda en el fondo. Tener una editorial, sacar una editorial. Pero eso también tiene que ver, yo creo, porque estaban entrando nuevas lecturas. Habían aparecido muchos, muchos escritores en ese momento. Te estoy hablando de diez años atrás.

Había ya algunos antecedentes de organizaciones, juntas digamos de varios editores, como que ya venía una tradición que era distinta a lo que existía con los Editores de Chile. Éramos todos más jóvenes y teníamos ganas de construir cosas distintas y de decir: mira, esto es lo que yo quiero publicar y no voy a publicar esto que está acá, no. Mi tema es la poesía, mi tema es la narrativa, mi tema es este, mi tema es la filosofía, ¡Ya! Vamos, tiene que ver con eso. (DK)

Arquetipo B: La construcción de lo diferente siguiendo el proceso de otras editoriales. 
Hay tres ideas que sostienen el sentido, una de ellas es similar a construir o elaborar, la otra es sinónimo de curiosidad intelectual y la tercera transita entre la imitación y la admiración, su combinación permite guiar un conjunto de prácticas en una ruta ya trazada por otros, y hay una frontera desde donde se señala el lugar al que no se quiere ir a trabajar en calidad de editor. En cuanto a la reconstrucción del discurso, la expresión de este arquetipo sería la siguiente: Ahí nos dimos cuenta de nuestra inquietud por hacer una editorial y admiramos lo ya hecho por las editoriales independientes. Y ese contenido se puede encontrar en opiniones como la que continúa:

Nace en un diplomado en el cual éramos los tres estudiantes. Era el diplomado en edición y publicaciones. Ahí, además, estaba siendo de ayudante en el diplomado y ahí nos conocimos. En el mismo diplomado siempre estuvo como la inquietud - al menos ahí nos dimos cuenta de que los tres entramos con esa inquietud- de hacer una editorial, más que entrar a trabajar a una editorial grande, sobre todo por una disconformidad con lo que se estaba publicando en Chile. Y al revés, por una admiración muy grande por las editoriales independientes que ya había en esas fechas, que eran menos de las que hay ahora, pero, claro, había muy importantes como: Calabaza del Diablo, Das Kapital y un poco, siguiendo ese ejemplo, querer nosotros unirnos a esa forma. $(\mathrm{O})$

Arquetipo C: La construcción de lo diferente gestionado por las mujeres.

Hay dos ideas que sostienen el sentido, una de ellas es similar a gestionar o administrar y la otra es sinónimo de mujer o femenina, su combinación conduce a una práctica feminista de los procesos productivos y creativos, y hay una frontera que busca distanciarse de las gestiones que se hacen desde lo masculino, lo heterosexual o lo normal. En cuanto a la reconstrucción del discurso, la expresión de este arquetipo sería la siguiente: La gestión de la editorial realizada por las mujeres para armar catálogos. Y ese contenido se puede encontrar en opiniones como la próxima:

Es que hay varias etapas de la editorial. Nosotros partimos siendo tres mujeres, yo me quedé de esa administración, y llegaron los chiquillos en el 2013. En principio estoy hablando del 2010. Había pocos espacios para publicar poesía, mujeres sobre todo, que era nuestra primera preocupación. Entonces partimos tratando de recopilar como voces fundamentales de la poesía en los ochentas, partimos con la Fariña, mezclando con poetas jóvenes, en algunos casos inéditos o que tenían un solo libro; y que la 
administración estuviera hecha por mujeres, que era una irregularidad en ese tiempo: una editorial sólo de mujeres.

Entrevistador: ¿buscaban darle un enfoque de género?

No pero sí la posibilidad de que la gente que armara catálogos fueran mujeres y que no hubiese prejuicios (...) Somos pocos, nosotros no tenemos ninguna ganancia. No recibimos plata de nadie, ni siquiera el diseñador, el único que recibe plata en esta dinámica es el contador, quince lucas mensuales, eso es todo. Nosotros no tenemos oficina, tenemos un chat en WhatsApp donde vemos la mayoría de las cosas: una cadena por correo electrónico mensual y es puro ímpetu no más. Nunca tenemos problemas porque yo estoy trabajando más que tú o yo vaya a más ferias que tú, los tres somos muy amigos, nos conocemos hace muchos años.

Nos conocíamos de antes. Yo fui profe él en la universidad, y él es el primer autor que publicamos. Nosotros con él trabajamos en la revista de la universidad, y él era director y yo era profe, y él ganó el concurso de la revista y ahí lo conocimos. Y bueno como no tenemos contrato no tenemos nada legalmente, los chiquillos no tienen ninguna relación legal, ellos no tienen otra alternativa que confiar en mí. Porque yo tengo la sociedad legal. (CT)

\section{Arquetipo D: Hacer libros como un medio de autoformación}

Hay tres ideas que sostienen el sentido, una de ellas es similar a crear o imaginar, la otra busca nombrar una situación de formación sin una guía, o autodidacta, y la tercera considera la elaboración de un libro como medio para. La combinación de estas ideas constituye la autogestión del conocimiento sin declarar una frontera y aspirando a la expansión del saber. En cuanto a la reconstrucción del discurso, la expresión de este arquetipo sería la siguiente: Nosotros hacemos libros como medio para expandir el conocimiento, usamos la auto-formación como ejercicio cotidiano de creación. Y ese contenido se puede encontrar en opiniones como la que continúa:

Nosotros hemos siempre señalado que esto de hacer libros es principalmente gimnasia cerebral, gimnasia creativa. Es un ejercicio permanente que se mantiene en el día a día como parte de un cotidiano. En términos técnicos, la base es el auto-didactismo y la necesidad de la auto-formación, el interés por lo que nosotros llamamos la autogestión del conocimiento, es decir, hacer libros para nosotros no constituye un 
fin sino un medio que nos permite adentrarnos en ciertos tópicos que nos interesan, aprehenderlos y compartirlos. Tiene un propósito también altruista de generar una mayor expansión en ciertos conocimientos que a nosotros nos interesan. (N/E)

\section{La amistad en las prácticas de trabajo}

Al igual como lo observó Price y Arnould (1999) y Cederholm y Hultman (2010), las relaciones de amistad se encuentran situadas en tiempos y espacios. En los editores esas condiciones suceden en la producción del libro y se caracterizan por la tensión entre la intimidad y la distancia, y es gracias a esa tensión que el editor puede reconocer el "oficio" del escritor y solicitar grados de confianza para co-construir y acompañar las actividades de creación literaria. O los momentos de edición como los llama Becker. Justamente por estas razones el editor puede ser definido como un experto en saber la calidad de la confianza que necesita para promover rutinas de trabajo, incluso, llega a estandarizar la confianza.

Entonces, la amistad comercial adopta formas típicas que son pertinentes al quehacer editorial según el grado de anonimato y universalidad que se requiera para realizar las formas de trato. Sin embargo, y a diferencia de lo que constataron los investigadores ya nombrados sobre el carácter extinguible de la relación de amistad comercial entre el proveedor de servicios y el cliente; en nuestro estudio observamos que la amistad comercial queda atada a las experiencias de creación y producción, por lo cual, ese campo de experiencias enrola a las personas en un memoria que puede ser trasladada y actualizada en los relatos de los encuentros entre editores, al mismo tiempo que la relación entre editor y escritor, o entre creadores, queda abierta y dispuesta para ser retomada, por ejemplo, para dialogar sobre las consecuencias de lo realizado.

A continuación, exponemos tres arquetipos que articulan la estandarización que usa el editor en sus rutinas de trabajo con los escritores y que, a nuestro entender, le permite ser reconocido como un experto en la administración de la tensión: intimidad y lejanía.

\section{Arquetipo E. La amistad como sustento del trabajo editorial.}

El proceso productivo permite que el editor conozca a la otra persona en su calidad de escritor, ambos pueden evaluar ese "lapso" "lento" como interacciones autárquicas cuyas partes concurren con autonomía, comensalidad y libertad. Así esas personas son sacadas de la calidad de individuos y esta nueva situación 
los conduce a cumplir la trama de papeles conocidos en el arte. Estas experiencias societarias crean responsabilidades, sentidos de pertenencia y memoria histórica, todas ajustadas a la trayectoria de la relación.

A continuación, cuando la construcción del contenido de la obra se ubica como el eje central el encuentro se orienta a reconocer los "caminos" para que el "autor" logre "completar su talento". También se reconoce un límite en la diversidad de estos encuentros, el cual es fijado por la "porfía" del "escritor" que expresa el "oficio" de manejar varios "caminos" para desplegar el "talento"; y si el editor cuenta con la "confianza" del escritor, entonces se vuelve a las relaciones autárquicas. Escritor y editor, de esta manera, reproducen un tercer factor, a saber: la fuerza colectiva. Usando la acepción de Adorno este componente los transforma en "tecnología" porque ese tercer factor es el tiempo donde sucede la gestión de los componentes de la idiosincrasia, donde se renueva "el ser-para-sí estético" (2004).

En cuanto a la reconstrucción del discurso, la expresión de este arquetipo sería la siguiente: El trabajo es lento, en ese lapso nos conocemos, la base de trabajo es la amistad porque facilita la comunicación y es todo lo contrario a la servidumbre. Y ese contenido se puede encontrar en opiniones como la que continúa: El trabajo es lento y en ese lapso si es que no nos conocemos nos vamos a hacer amigos. Igual puede sonar extraño pero la base de trabajo para nosotros es la amistad porque consideramos que es todo lo contrario a la servidumbre. Es todo lo contrario (...) la idea es que también seamos sujetos que también seamos individuos (...) parte de nuestra lectura, de nuestra visión por así decirlo, de una economía no capitalista, anticapitalista, parte también por esa relación donde tú también estás haciéndote responsable de este producto.

No es que yo sea alguien que tenga que hacer este trabajo y tú tengas que hacer otro separado, sino que tú también vas a estar dentro de la elaboración misma del libro. Nos juntamos y tomamos once o nos sentamos a conversar sobre otras cosas; y así en el fondo vamos generando un lazo que ya una vez que el libro está publicado también permite que el mismo autor, si desea, pueda participar económicamente del libro, venderlo él. La comunicación es algo que se logra siempre con la amistad. En el fondo no es ser los mejores amigos, pero sí tener la franqueza, la sinceridad, la transparencia en el proceso. Todo ese conjunto de elementos que colaboran con tener una relación humana un poco más igual. (E/N) 
Arquetipo F. La amistad como situación donde se plantean soluciones a los problemas del proceso productivo.

Los involucrados realizan los criterios de evaluación que han aprendido a usar en circunstancias y organizaciones diferentes a las basadas en la amistad comercial, para revisar los productos de la editorial a la cual pertenecen, así detectan deficiencias y proponen innovaciones. En cuanto a la reconstrucción del discurso, la expresión de este arquetipo sería la siguiente: Fue una amiga, nos mira y nos dice que debemos cambiar porque tenemos que llegar más lejos. Y ese contenido se puede encontrar en opiniones como las próximas:

\section{Opinión 1}

Entrevistador: El logo, ¿a quién se le ocurre? ¿Cómo nace?

Fue cambiando, justo aquí tienes los dos. El logo, bueno, éste, salió de una amiga que al hacer nuestro primer libro que no fue un libro comercial. El primer libro del dos mil once, cuando no existía la editorial. Yo entrevisté a mi abuelo antes que se muriera, era yugoslavo y arrancó de la primera guerra mundial y tiene una historia bien trágica y nadie la conocía, lo entreviste y escribí una novela, y esa novela la imprimimos sin código de barra, sin nada, como para mi familia. Ahí la diseñadora nos hizo una adaptación del logo de la revista. Y seguimos con eso, avanzamos y de repente llega un momento como el dos mil quince, que nuestro diseñador, que siempre fue publicista además, nos mira y nos dice: no podemos seguir con este logo es un desastre. La editorial empezó a crecer y ya no le vendíamos los libros a los amigos, teníamos más personas y teníamos que formalizarlo y llegar más lejos, más reconocible. (P)

\section{Opinión 2}

Son relaciones amorosas furtivas. Algunas perduran en el tiempo, pero cada libro es una experiencia en sí misma. Entre autor y editor, eso sí, debe existir un plano compartido determinado por las complicidades lectivas más que por el gusto. Hay un mapa de filiación entre estas dos figuras cuya arquitectura depende de la capacidad de desdoblarse, de salirse de sí mismo. En mi vida personal, fuera de lo laboral, casi no leo narrativa. Soy más de ensayos filosóficos, diarios de vida y poesía. La narrativa para mí es parte del oficio del lector; sí, edito novelas, pero mantengo esa distancia. Cuando hablo de la capacidad de desdoblarse me refiero a poder observar ese mapa de filiación con la menor cantidad de sesgos. La idea es mostrarle nuevos caminos al autor, complementar su talento con una perspectiva ajena y a partir de entonces, dialogar con él. 
Como te decía, cada libro es un territorio particular. Hubo un autor que me mandó su trabajo en un archivo y casi no hubo que meterle mano. En el reverso de esta historia, hay autores con los que llevo trabajando años y cada conversación es una pelea, pasa que mientras más oficio tienen más porfiados se ponen, pero eso está bien en la medida en que el editor, yo, cuente con su confianza (Editorial A, entrevista en prensa)

\section{Arquetipo G. La amistad como resistencia.}

La amistad comercial crea y reproduce un espacio socioafectivo que anima a los propietarios de la editorial a narrar las experiencias de fracasos, exclusiones y los juicios sobre los otros integrantes de los mundos del arte que fijan su ruta para lograr el éxito hedonista. Así, fijar la posición de cada cual permite la unión de sentimientos, la diferenciación y promueve una comunidad de trabajo que se relata a sí misma. En cuanto a la reconstrucción del discurso, la expresión de este arquetipo sería la siguiente: Hemos resistido harto, en ningún momento hemos flaqueado; a nosotros no nos importa la competencia, nosotros trabajamos con la noción de comunidad. Y ese contenido se puede encontrar en opiniones como la siguiente:

Yo creo que nosotros hemos aportado a que haya una editorial con discurso y que no sea como una improvisación porque todo discurso tiene un nivel de improvisación, pero sí nosotros tenemos un catálogo coherente con el discurso que tenemos y con lo que uno hace como editor. Los tres hemos resistido harto a un montón de cosas y tenemos resistencia al mercado como bien potente, y en ningún momento hemos flaqueado en eso. Eso ha significado mantener el formato y ahora han aparecido otras editoriales que están haciendo el mismo formato: somos como los abuelos. A nosotros no nos importa la competencia, no estamos ni ahí. De hecho, como que en general si aparecen otras editoriales con igual formato tenemos la cuestión como de apoyarlos.

Hace poquito abrió una editorial, yo compré, la subí a Facebook, como tratando de hacerle publicidad. Nosotros trabajamos más como con la noción de comunidad que con la noción de competencia. Esa noción de comunidad tiene que ver con cómo nos vinculamos con los autores, porque no tenemos una relación económica porque ellos tampoco tienen contrato. (CT) 
Al cerrar esta sección de datos, subrayamos que los arquetipos que hemos presentado ponen énfasis en los siguientes códigos sociolingüísticos: oficio, sujeto y trabajo. Estos códigos son cualificados por las siguientes nociones: "amistad", "responsable", "amorosa" y "confianza". En oposición a estos criterios y construyendo una frontera que limita la representación de la amistad comercial, se inicia otro campo semántico articulado por los códigos de: holgazán y objeto, y es probable que existan representaciones de experiencias que sí participan en la cadena del libro y/o en el mercado de bienes simbólicos, y donde participan significativamente los siguientes criterios: "servidumbre", insensato, odiosa e inseguridad.

\section{Conclusión}

Las interpretaciones que hemos subrayado como parte del eje semántico "hacer libros porque sí", ayudan a reconocer expresiones de la amistad comercial que son anteriores a las prácticas de trabajo o que se fraguan en el modo de producción, y advertimos que indican un estado autárquico donde se crea la responsabilidad, se fomenta el sentido de pertenencia y se articula una memoria compartida.

Estas consecuencias pueden ejercer una inflexión en las prácticas laborales y comerciales. Por lo cual, los editores considerarían que hacer un libro representa una secuencia de prácticas creativas y reflexivas guiadas por una disposición libre y voluntaria, semejante a una rutina lúdica. Así, hacer un libro es diferente del esfuerzo que cada persona realiza para mover su voluntad y llegar a ese propósito. Parafraseando a Luckmann (2008), podríamos agregar que la amistad comercial participa en las interacciones donde se hilvana el mundo del arte con las subjetividades y las esferas del comercio, y de esa forma también se redefine la idea de trabajo porque la fuerza que se necesita para transformar la realidad es interpretada desde la representación simbólica de la amistad.

Desde esta fuerza productiva que acoge la vida, diría Simmel, el editor está conducido por las "ganas", la "inquietud", el "querer", la "preocupación" y la "necesidad"; mientras que se aleja del "desgano", la "tranquilidad", el “desprecio", la "calma”, la "opulencia” y la "apatía". Y nosotros, al observar esa ruta de interpretación, identificamos las diferencias entre una esfera de la realidad donde el libro es parte del bien común que expresa la bibliodiversidad, y otra esfera de la realidad donde el libro es una mercancía para el consumo rápido y es medio para el éxito comercial. 
Por otro lado, la experiencia de sociabilidad lúdica vivida en la elaboración de un libro pasa a ser la unidad elemental desde donde emerge la asociación, el Nosotros. En este caso, la Cooperativa de editores de la Furia. Para los propósitos de este artículo, lo relevante es que en la asociación se erigen las fuentes de la legitimidad de los principios reivindicados por los editores, los cuales deben ser considerados por las personas que recién llegan a la gestión de una editorial independiente. En esos términos, podemos tratar la sociabilidad lúdica como un tipo específico de contingencia societaria que conduce a los involucrados a negociar los alcances de la intimidad y la distancia, también porque ayuda a fijar las formas de transmitir las ideas y experiencias, y porque ofrecen oportunidades para realizar nuevas formas de llevar a cabo las cosas.

La relación primaria entre el editor y su quehacer, comprendida y evidenciada, además, en el propio lenguaje de los editores aquí entrevistados, refleja las lógicas inconclusas de actores que intentan ir configurando un sistema de comprensión propio (a través de sus catálogos) frente la homogeneización de la realidad de un sistema que busca aplanar e incluso censurar las voces disidentes que debe expresar una democracia.

Finalmente, la revisión de la amistad comercial nos ha permitido reconocer las bases de las exigencias del sentimiento del deber, incluso hemos visto que los editores usan el conjunto de código sociolingüísticos para nombrar las experiencias donde ellos disputan los sentidos a los cuales recurren las personas que están más allá de su comunidad evocada, para indicar los componentes de su realidad, incluyendo las conductas que están en contra del mecanismo de mercado de oferta-demanda-precio y que buscan recomponer los compromisos o, al menos, intentan colonizar las controversias para politizar y desalentar el cálculo utilitario.

\section{Referencias bibliográficas}

Becker, H. (2008). Los mundos del Arte. Sociología del trabajo artístico. Universidad Nacional de Quilmes.

Bialakowsky, A. (2012). Repensar la comunidad: la teoría sociológica clásica y la perspectiva de Niklas Luhmann en la intersección de dos problemas fundantes. En Pablo de Marinis (coord.) Comunidad: estudios de teoría sociológica (pp. 369-416). Prometeo. 
Bourdieu, P. (1990). El campo literario. Prerrequisitos críticos y principios de método. Criterios (La Habana), (25-28), 20-42.

Bourdieu, P. (2002). Campo de poder, Campo Intelectual. Itinerario de un concepto. Montressor.

Callon, M., Méadel, C, y Rabeharisoa, V. (2002). The economy of qualities. Economy and Society, 31 (2), 194-217. doi.org/10.1080/03085140220123126

Callon, M. (2007). An Essay on the Growing Contribution of Economic Markets to the Proliferation of the Social. Theory, Culture and Society, (139-163). doi.org/10.1177/0263276407084701

Cederholm, A. and Hultman, J. (2010). The Value of Intimacy-Negotiating Comercial Relationships in Lifestyle Entrepreneurship. Scandinavian Journal of Hospitality and Tourism, 10 (1). 16-32.

Hultman, J. and Andersson, E. (2012). The Boundary Work of Commercial Friendship. In conference "Kultur Natur: Konferens för kulturstudier i Sverige", organised by the Advanced Cultural Studies Institute of Sweden, Norrköping 15-17 June 2009. Linköping University, 131-141.

Dreher, J. (2012). Superando la trascendencia del mundo intersubjetivo: reflexiones fenomenológicas sobre la amistad. En Belvedere, C. (Ed.) La constitución de lo social. Aportes para el diálogo entre la sociología y la fenomenología. (pp.76-96). Los Polvorines: Universidad Nacional General Sarmiento.

Durston, J. (2000). ¿Qué es el capital social comunitario? Revista de la Cepal, Serie Políticas Sociales División de Desarrollo Social, (38), 47-60.

(2001). Capital social, parte del problema, parte de la solución. Su papel en la persistencia y en la superación de la pobreza en América Latina y el Caribe. En , Documento de referencia DDR/1, 20 de septiembre de 2001: Santiago, Chile: CEPAL.

(2005). ¿Apitutados o apechugadores? El clientelismo político en el campo chileno. En Porras, J. y V. Espinoza (comp.). Redes: enfoques y aplicaciones del análisis de redes sociales (S/pp). Universidad Bolivariana.

Gibson, K., y Graham, J. (2011). Una política poscapitalista. Pontificia Universidad Javeriana, Siglo del Hombre.

Gómez, N., Rojas, P., Benítez, M., y Sánchez, A. (2019) La autogestión en la diversidad económica. Cooperativas, clubes y talleres productivos en la provincia del Marga Marga, región de Valparaíso de Chile. Revista CUHSO 29(1), 191-224. https://doi.org/10.7770/cuhso.v29i1.1616

Honneth, A. (1999). Comunidad. Esbozo de una historia conceptual. ISEGORÍA (20). 5-15. https://doi.org/10.3989/isegoria.1999.i20.89

Luckmann, T. (2008). Conocimiento y sociedad. Ensayos sobre acción, religión y comunicación. Trotta. 
Max-Neef, M., Elizalde, A., and Hopenhayn, M. (1993). Desarrollo a Escala Humana. Conceptos, aplicaciones y algunas reflexiones. Nordan-Comunidad.

Polanyi, K. (2009). El sustento del hombre. Capitán Swing.Salas, R. (2006). El mundo de la vida y la fenomenología sociológica de Schütz. Apuntes para una filosofía de la experiencia. Revista de Filosofía, (15), 167-199.

Silva, M. (2019). Independencia, autogestión, literatura y realidad en la revista chilena La Calabaza del Diablo (1998-2004). Revista de Humanidades, (39), 235-265.

Simmel, G. (2002). Cuestiones fundamentales de sociología. Gedisa.

(2004). Intuición de la vida. Cuatro capitulos de metafísica. Terramar.

Symmes, C. (2013). Fundar la Asociación de Editores independientes de Chile: una estrategia de resistencia colectiva. Comunicación y Medios, (27), 129-146.

(2015). Editar (en) el Chile post-dictadura: Trayectorias de la edición independiente. Nuevo Mundo Mundos Nuevos Questions du temps présent, https://doi.org/10.4000/nuevomundo.68211

Torterola, E. (2012). Lazo social y metrópoli. La comunidad en los orígenes de la sociología urbana: Georg Simmel y Robert E. Park. En Pablo de Marinis (coord.) Comunidad: estudios de teoría sociológica (pp.109-140) Prometeo.

Watier, P. (2005). Georg Simmel. Sociólogo. Nueva Visión. 